\title{
Endoscopic appearances of the rectal mucosa of patients with Crohn's disease visualised with a magnifying colonoscope
}

\author{
K MAKIYAMA, M K BENNETT, AND D P JEWELL \\ From the Gastroenterology Unit Radcliffe Infirmary, Oxford
}

SUMmARY The magnified endoscopic appearances of the rectum are described in 12 patients with Crohn's disease with apparent rectal sparing on sigmoidoscopy. Five of them had minor abnormalities on colonoscopy but the remaining seven had a normal rectum. After the application of $0.2 \%$ methylene blue, examination using a magnifying endoscope (Olympus CF-HM) revealed characteristic 'worm-eaten' appearances in $75 \%$ of the patients regardless of the activity of their disease. Histological examination of biopsy specimens from these lesions showed marked inflammatory changes, and granulomas or microgranulomas were found in $75 \%$. Inflammatory changes were not seen in mucosa which appeared normal on magnifying colonoscopy although microgranuloma were found in three cases. These observations confirm the focal nature of Crohn's disease and may suggest that the early lesions are mucosal and frequently contain granulomata.

The inflammation of Crohn's disease is characteristically discontinuous with diseased segments of intestine separated by apparently normal segments. In particular, the rectum is frequently normal on endoscopic examination although microgranuloma may be found if biopsy specimens are taken. ${ }^{1}$ Recently, a patient with Crohn's disease has been reported in whom the rectum, which appeared normal at endoscopy, was examined with a magnifying colonoscope after the application of methylene blue to the mucosa. ${ }^{2}$ A remarkable number of abnormalities were seen which were due to distortion and destruction of the epithelial pits and were called 'worm-eaten' appearances. The purpose of the present study was to extend these observations and to make a detailed histological analysis of these lesions.

\section{Methods}

\section{PATIENTS}

Twelve patients with Crohn's disease affecting the ileum or colon, but without radiological or sigmoidoscopic evidence of rectal involvement,

Address for correspondence: Dr D P Jewell, Gastroenterology Unit, Radcliffe Infirmary, Oxford OX2 $6 \mathrm{HE}$.

Received for publication 19 May 1983 were examined with a magnifying colonoscope (Olympus CF-HM). The diagnosis had been previously established by clinical, radiological, and pathological criteria. There were nine women and three men. The mean age was 32 years (range 20-71 years). Details of disease distribution are shown in Table 1.

\section{COLONOSCOPIC EXAMINATION}

All patients were examined without any form of preparation in order to avoid inducing minor changes in the rectal mucosa. The presence of any perianal complications was noted. The rectum was then examined with the colonoscope using the standard endoscopic magnification. The presence of epithelial ulcers, spotty reddening with localised oedema, vascular abnormalities, granularity, and adherent blood or mucus, was noted. Methylene blue $(0.2 \%)$ was then sprayed onto the mucosa and the rectum re-examined using magnification up to a maximum of $\times 35$. The area examined extended above and below the second valve of Houston. Biopsy specimens were obtained from abnormal areas as well as areas of mucosa which appeared normal even at the highest magnification.

Biopsy specimens were fixed in an acidic formalin-saline solution, ${ }^{3}$ embedded in paraffin wax, and 35 sections were cut from each specimen. 
Table 1 Patient details and endoscopic findings

\begin{tabular}{|c|c|c|c|c|c|c|c|c|}
\hline \multicolumn{2}{|l|}{ No } & \multicolumn{2}{|c|}{$\begin{array}{l}\text { Age and } \\
\text { sex }\end{array}$} & \multirow{2}{*}{$\begin{array}{l}\begin{array}{l}\text { Extent of } \\
\text { disease }\end{array} \\
\text { Colitis }\end{array}$} & \multirow{2}{*}{$\begin{array}{l}\text { Activity } \\
\text { Active }\end{array}$} & \multirow{2}{*}{$\begin{array}{l}\text { Rectal } \\
\text { appearances on } \\
\text { standard endoscopy }\end{array}$} & \multirow{2}{*}{$\begin{array}{l}\text { Magnifying } \\
\text { colonoscopy of } \\
\text { rectum presence } \\
\text { of 'worm-eaten' } \\
\text { appearance } \\
\text { A-type }\end{array}$} & \multirow{2}{*}{$\begin{array}{l}\begin{array}{l}\text { Granuloma } \\
\text { or micro- } \\
\text { granuloma }\end{array} \\
++\end{array}$} \\
\hline 1 & LT & 46 & $\mathbf{F}$ & & & & & \\
\hline 2 & MS & 25 & $\mathbf{F}$ & Ileocolitis & Inactive & Aphthoid ulcers & A-type & + \\
\hline 3 & EP & 22 & $\mathbf{F}$ & Sigmoiditis & Active & Hyperaemic mucosa & A-type & + \\
\hline 4 & $\mathrm{HC}$ & 26 & F & Colitis & Inactive & Normal & $\begin{array}{l}\text { A-type } \\
\text { (white spots) }\end{array}$ & - \\
\hline 5 & IH & 21 & $\mathbf{M}$ & Ileocolitis & Inactive & Normal & $\begin{array}{l}\text { A-type } \\
\text { (white spots) }\end{array}$ & + \\
\hline 6 & $\mathrm{JC}$ & 52 & $\mathbf{F}$ & Colitis & Active & Aphthoid ulcers & B-type & + \\
\hline 7 & MA & 71 & $\mathrm{~F}$ & Colitis & Active & $\begin{array}{l}\text { Irregl vascu } \\
\text { adh mucosa }\end{array}$ & B-type & + \\
\hline 8 & FB & 65 & $\mathbf{F}$ & Ileitis & Inactive & Normal & B-type & No biopsy \\
\hline 9 & PS & 34 & $\mathbf{F}$ & Ileitis & Inactive & Normal & B-type & - \\
\hline 10 & SE & 26 & $\mathbf{M}$ & Ileitis & Inactive & Normal & Absent & - \\
\hline 11 & GP & 20 & $\mathbf{M}$ & Colitis & Active & Normal & Absent & + \\
\hline 12 & MJ & 20 & $\mathbf{F}$ & Ileitis & Inactive & Normal & Absent & - \\
\hline
\end{tabular}

Sections were $4 \mu$ thick and were routinely stained with haematoxylin and eosin. Each section was assessed for inflammatory infiltrate and its distribution, and for the presence of granulomata or microgranulomata as defined by Whitehead. ${ }^{4}$

\section{Results}

Table 1 shows the detailed results from the 12 patients. Five of them were shown to have minor abnormalities on colonoscopy at standard magnification. These changes included hyperaemia, adherent mucus, and small aphthoid ulcers. Four of these five patients were known to have colonic involvement (three with colitis, one with ileocolitis). The remaining seven patients were found to have no abnormality in the rectum (four patients with ileitis, two with colitis, and one with ileocolitis).

Figure 1 shows the magnified appearances of normal rectal mucosa after an application of $0.2 \%$ methylene blue. The papillae and the pits of the epithelial glands are well shown. In nine $(75 \%)$ of the 12 patients with Crohn's disease abnormal appearances were seen at high magnification in areas of mucosa which had appeared normal on standard colonoscopy even after spraying with methylene blue. These abnormalities were similar to the 'worm-eaten' appearances previously described ${ }^{2}$ and were of two types. Type A consisted of an area where the normal 'honeycomb' pattern became distorted and the mucosa failed to take up the dye (Figs 2a,b). This abnormal area has a distinct border and is clearly demarcated from the surrounding normal mucosa. Type B is similar but the boundary between abnormal and normal mucosa is blurred and indistinct. Five of the nine patients with abnormal appearances had type A lesions and four had type B lesions. Occasionally, both types were seen in the same patient. For example, patient 5 (IH) had predominantly type A lesions but had a few small type $B$ lesions scattered around the rectum. These abnormal mucosal appearances were seen whether or not the disease was active and they did not correlate either with the extent of disease or with corticosteroid or sulphasalazine therapy. In two patients, larger lesions were seen which looked like 'white spots'. Once again, these were only seen following the application of methylene blue (Fig. 3). These 'white spots' appeared to be a more advanced lesion than the 'worm-eaten' lesions as they were larger and were slightly raised because of local oedema.

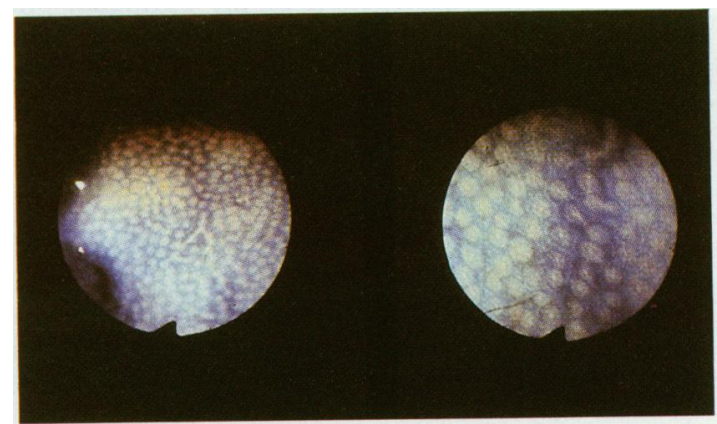

Fig. 1 Normal rectal mucosa visualised with magnifying colonoscope after methylene blue application. Low and high power appearances are shown. 
Fig. 2 Appearances of type $A$ (a) and type $B(b)$ 'worm-eaten' lesions.

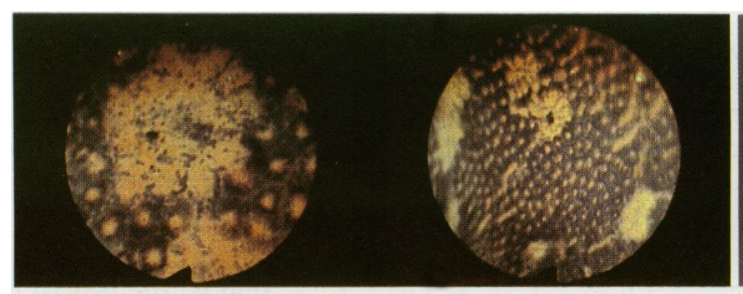

$a$

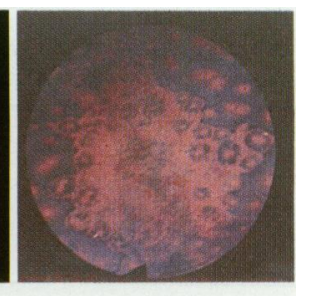

$b$
Histological examination of biopsies taken from abnormal areas seen on magnifying colonoscopy ('worm-eaten' areas) showed marked inflammatory changes compared with biopsies from adjacent mucosa which was endoscopically normal (Table 2). Furthermore, in the great majority of cases $(75 \%)$ mucosal granulomata or microgranulomata were found in the 'worm-eaten' areas and only in three cases $(30 \%$; cases 3,7 , and 11 ; Table 1 ) was a microgranuloma found in endoscopically normal mucosa. In one patient, both a microgranuloma and a fully formed granuloma were found. All the granulomata and microgranulomata were superficial in the upper half of the mucosa. The inflammatory infiltrate was patchy and was distributed throughout the mucosa and extended into the submucosa. There was no histological difference between type $\mathrm{A}$ and type B endoscopic abnormalities either with respect to the inflammatory infiltrate or the presence of granulomata. One patient (no 1) had a type B lesion which was ulcerated on histological examination. Biopsy specimens from the two patients with 'white spots' showed rather more inflammatory change than types A and B but no specific features.

\section{Discussion}

It is well recognised that rectal biopsies may show diagnostic features in patients with Crohn's disease even when the rectal mucosa appears normal on sigmoidoscopy. For example, Korelitz et $a l^{5}$ reported that $18 \%$ of 99 patients with Crohn's disease with a macroscopically normal rectum had granulomata in rectal biopsy specimens. Subsequently, similar studies have reported a frequency of $10 \%{ }^{6}$ and $2.9 \% .^{7}$ If all series are considered the overall frequency with which granulomata can be found in rectal mucosa which appears to be uninvolved is about $10 \% .^{15-10}$

The present study has shown that, using a magnifying colonoscope, abnormalities can frequently be detected in the rectal mucosa of patients with Crohn's disease which had appeared normal on sigmoidoscopic examination. These abnormalities are mostly seen after the application of methylene blue and consist of distorted architecture of the gland pits and failure to take up the dye. Since different morphological appearances were recognised (type A, type B, white spots), they

Fig. 3 (a) Endoscopic view of an apparently normal rectal mucosa in patient with Crohn's disease. (b) Same view after methylene blue showing presence of white spots.
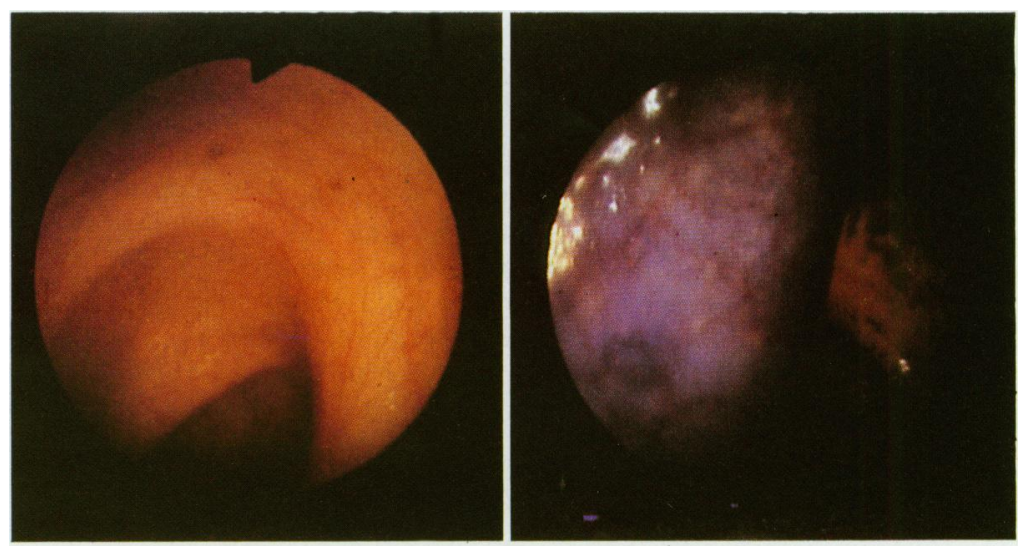

$a$ 
Table 2 Histological analysis of 'worm-eaten' appearances and adjacent normal mucosa

\begin{tabular}{|c|c|c|c|c|}
\hline \multirow[b]{2}{*}{$n$} & \multicolumn{3}{|c|}{$\begin{array}{l}\text { 'Worm-eaten' } \\
\text { appearance }\end{array}$} & \multirow[b]{2}{*}{$\begin{array}{l}\text { Normal } \\
\text { mucosa }\end{array}$} \\
\hline & $\begin{array}{l}\text { Type } \\
A\end{array}$ & $\begin{array}{l}\text { Type } \\
\text { B }\end{array}$ & $\begin{array}{l}\text { Types } A \\
\text { and } B\end{array}$ & \\
\hline & 5 & 3 & 8 & 10 \\
\hline \multicolumn{5}{|l|}{$\begin{array}{l}\text { Mononuclear cell } \\
\text { infiltrate }\end{array}$} \\
\hline Definite & 1 & 2 & 3 & 0 \\
\hline Equivocal & 2 & 0 & 2 & 8 \\
\hline \multicolumn{5}{|l|}{ Mononuclear patchy } \\
\hline inflammation & 2 & 3 & 5 & 2 \\
\hline Lymphoid aggregates & 5 & 2 & 7 & 8 \\
\hline Granuloma & 1 & 1 & 2 & 0 \\
\hline Microgranuloma & 3 & 2 & 5 & 3 \\
\hline Oedema & 2 & 0 & 2 & 2 \\
\hline Mucus depletion & 2 & 0 & 2 & 0 \\
\hline
\end{tabular}

have been described as such. They may represent the same basic lesion, however, and there were no histological differences between them. These lesions have not been seen in patients with the irritable bowel syndrome (K Makiyama and D P Jewell, unpublished observations). For patients with Crohn's disease, no data are available on the number of lesions present in a given area of mucosa and such data would be difficult to obtain owing to the high magnification required to visualise them. Biopsies from these lesions showed a marked degree of inflammatory changes compared with biopsy specimens from adjacent normal mucosa. These changes included mononuclear cell infiltration, mucus depletion, oedema, and aggregation of lymphocytes. The striking histological finding was the very high frequency with which granulomata or microgranulomata were found in biopsy specimens from the 'worm-eaten' lesions (75\%) compared with their frequency in biopsy specimens from adjacent normal mucosa $(30 \%)$. The frequency with which granulomata were observed was independent of disease activity, assessed clinically, and anatomical distribution of the major disease segment.

These results support the hypotheses that the whole of the gastrointestinal mucosa may be abnormal in patients with Crohn's disease, even when the disease appears to be localised to a well defined segment of intestine. ${ }^{11} 12$ Furthermore, it seems a likely hypothesis that 'worm-eaten' lesions, which are only visualised at high magnification after spraying the mucosa with methylene blue, represent the earliest lesions of Crohn's disease. It is therefore of great interest that granulomata or microgranulomata can be found in the majority of these lesions. In terms of pathogenesis, these superficial lesions suggest an epithelial reaction to a luminal stimulus. Associated with the epithelial reaction that is, the loss of methylene blue staining - there is an inflammatory infiltrate, typical of Crohn's disease, which might well represent the response to an antigen.

\section{References}

1 Rotterdam H, Korelitz BI, Sommers SC. Microgranulomas in grossly normal rectal mucosa in Crohn's disease. Am J Clin Pathol 1977; 64: 550-4.

2 Makiyama K, Kitukawa K, Tomita $S$ et al. Firm endoscopic changes in the rectal mucosa of Crohn's disease. A case report. Gastrointest Endosc 1981; 23: 1578-84.

3 Curran RC, Gregory J. Effects of fixation and processing an immunohistochemical demonstration of immunoglobulin in paraffin sections of tonsil and bone marrow. J Clin Pathol 1980; 33: 1047-57.

4 Whitehead R. Mucosal biopsy of the gastrointestinal tract. Philadelphia: Saunders, 1979.

5 Korelitz BI, Sommers SC. Rectal biopsy in patients with Crohn's disease. Normal mucosa on sigmoidoscopic examination. JAMA 1977; 237: 2742-4.

6 Surawicz CM, Meisel JL, Ylrisaker T, Saunders DR, Rubin CE. Rectal biopsy in the diagnosis of Crohn's disease. Value of multiple biopsies and serial sectioning. Gastroenterology 1981; 80: 66-71.

7 Hill RB, Kent TH, Hamsen RN. Clinical usefulness of rectal biopsy in Crohn's disease. Gastroenterology 1979; 77: 938-44.

8 Present DH, Chapman ML, Cohen N, Janowitz HD. The correlation of sigmoidoscopy and rectal valve biopsy in granulomatous disease of the small bowel. [Abstract.] Gastroenterology 1967; 52: 1113.

9 Gear EV Jr, Dobbins WO III. Rectal biopsy: a review of its diagnostic usefulness. Gastroenterology 1968; 55: 522-44.

10 Morson BC. Rectal and colonic biopsy in inflammatory bowel disease. Am J Gastroenterol 1977; 67: 417-26.

11 Dunne WT, Cooke WT, Allan RN. Enzymatic and morphometric evidence for Crohn's disease as a diffuse lesion of the gastrointestinal tract. Gut 1977; 18: 290-4.

12 Goodman MJ, Skinner JM, Truelove SC. Abnormalities in the apparently normal bowel mucosa in Crohn's disease. Lancet 1976; 1: 275-8. 